\title{
Biogeography of the water flea Daphnia O. F. Müller (Crustacea: Branchiopoda: Anomopoda) on the Indian subcontinent
}

\author{
Sameer M. PADHYE,${ }^{1 *}$ Alexey A. KOTOV,${ }^{2,3}$ Neelesh DAHANUKAR, ${ }^{4}$ Henri J. DUMONT ${ }^{5,6}$ \\ ${ }^{1}$ Wildlife Information Liaison Development Society, Coimbatore 641035, India; ${ }^{2}$ A. N. Severtsov Institute of Ecology and Evolution, \\ Leninsky Prospect 33, Moscow 119071, Russia; ${ }^{3}$ Kazan Federal University, Kremlevskaya 18, Kazan 420000, Russia; ${ }^{4}$ Indian Institute \\ of Science Education and Research, G1 Block, Dr. Homi Bhabha Road, Pashan, Pune 411008, India; ${ }^{5}$ Biology Department, Gent \\ University, Ghent, Belgium; ${ }^{6}$ Department of Ecology and Hydrobiology, Jinan University, Guangzhou, China \\ *Corresponding author: sameer.m.padhye@gmail.com
}

\begin{abstract}
Studies on Daphnia distribution in Indian subcontinent have been few and regionally restricted despite Daphnia being by far the most studied cladoceran. We here present a first biogeographical assessment of the genus on the Indian subcontinent (Afghanistan, Pakistan, India, Nepal, Bhutan, Bangladesh and Sri Lanka). We collected all pertinent literature and considered nineteen bioclimatic variables along with latitude, longitude, and altitude for statistical analysis of factors governing distribution in space. Significant variables (determined by Kruskal Wallis test) were tested by nonparametric multivariate analysis of variance (PERMANOVA) to clarify whether Daphnia species had specific environmental requirements. Canonical correspondence analysis was used to understand how environmental variables affected distribution. Eight Daphnia (Ctenodaphnia) and 4 Daphnia s.str. occurred at 100 different localities. The variables temperature, altitude and latitude differed among species and so did their bio-climatic requirements. Daphnia distribution responded positively to altitude and negatively to a decrease in latitude and temperature. We confirm the existence of three complexes of Daphnia in the Indian subcontinent: i) widely distributed species and species complexes; ii) high altitude endemics; and iii) low latitude D. (Ctenodaphnia) species.
\end{abstract}

Key words: Ctenodaphnia; Daphnia magna; Daphnia pulex; Himalayas; oriental zone; Western Ghats.

Received: March 2016. Accepted: June 2016.

\section{INTRODUCTION}

The Cladocera (Crustacea: Branchiopoda) constitute an ancient group of primarily freshwater crustaceans whose major differentiation may have occurred before the Permian (Kotov and Taylor, 2011). Until the Late Cenozoic, the Cladocera (and other Branchiopoda) are believed to have been much species-richer than today (Kerfoot and Lynch, 1987; Korovchinsky, 2006). As a result of climatic changes in the Tertiary, maximum cladoceran species richness is now concentrated in the subtropical zone of both hemispheres and at higher elevations within the true tropics (Korovchinsky, 2006).

Daphnia (Anomopoda: Daphniidae) is among the best-studied freshwater organisms (Lampert, 2011). It has an origin estimated at more than $200 \mathrm{Myr}$ (Taylor et al., 1996; Kotov and Taylor 2010, 2011). Currently the genus is classified into three sub-genera (Adamowicz et al., 2009) with 361 formally described species in toto of which c. $24 \%$ are considered valid (Kotov, 2015). Among them, only few inhabit the lowland equatorial zone (Fernando, 1980; Fernando and Kanduru,1984; Benzie. 2005), with species occurring only above particular altitudes (Dumont, 1980; Green, 1995).

The biogeographical patterns observed in many Daphnia species in the Neotropics, Neartic, Paleartic and Afrotropical regions have been assessed relatively adequately
(Ishida and Taylor, 2007; Mergeay et al., 2008; Adamowicz et al., 2009) but little information is available on the Indian subcontinent. Yet, this region is interesting for biogeography because of i) a complex geological history; ii) a wide range of altitudes; and iii) a strong seasonality with a distinct rainfall season (Monsoon) (Mani, 1974; Briggs, 2003). This has allowed the formation of various biomes, ranging from tropical to Alpine forests and deserts (Mani, 1974) resulting in a combination of endemic, Oriental, Palaearctic as well as Gondwanan biota (Gower et al., 2002; Whatley and Bajpai, 2006; Koehler and Glaubrecht, 2007; Kulkarni and Pai, 2016). Their presence has been explained by hypotheses like the 'Indian raft' and 'Out of Asia into India' (Chatterjee and Scotese, 1999; Karanth, 2003), but relevance of such scenarios for passively dispersed zooplankton is uncertain.

Here, our aim was to analyze Daphnia distribution on the Indian sub-continent, discuss associations between species and environmental variables, and evaluate the relative importance of selected climatic variables in elucidating the distributional patterns observed.

\section{METHODS}

\section{Study area}

Our study area (Fig. 1) extends from Afghanistan and Pakistan to the west, India in the centre, Nepal and Bhutan 
to the east and Sri Lanka to the south (between $38^{\circ} \mathrm{N}$ to $4^{\circ} \mathrm{N}$ latitudes and $60^{\circ} \mathrm{E}$ to $98^{\circ} \mathrm{E}$ longitudes). Geographically, this region includes the Hindukush in the northwest, Himalayas from north till north-east; Indo-Gangetic plains on the Himalayan slopes, a central plateau region (like Deccan plateau) flanked by the more continuous Western and more fragmented Eastern Ghats, and a peninsular region bordered by a narrow coastline (Mani, 1974).

An altitudinal gradient is seen as we move down along the latitude. The altitude of the Himalayas ranges from $6600 \mathrm{~m}$ asl in northern and northwestern part (Tibetan Himalayas) to $900-1200 \mathrm{~m}$ asl in the more southern Sivalik ranges. The Central Indian subcontinent (plateau region) has an altitudinal range of 350-900 $\mathrm{m}$ asl, the highest peak in peninsular region of the subcontinent reaches nearly $2600 \mathrm{~m}$ asl. The southernmost region of the subcontinent, viz. Sri Lanka, has an altitudinal range of 0-2500 m.

Most of the Indian subcontinent has a monsoon climate, with rains for 3-4 months, usually from June till September/October. Part of the southern region and the north-eastern zone also receive rains from the retreating monsoon in November and December.

\section{Data collection and GIS analysis}

Data were gathered through mining of the literature published on Daphnia faunistics, taxonomy and biology. We used a conservative approach in selecting literature

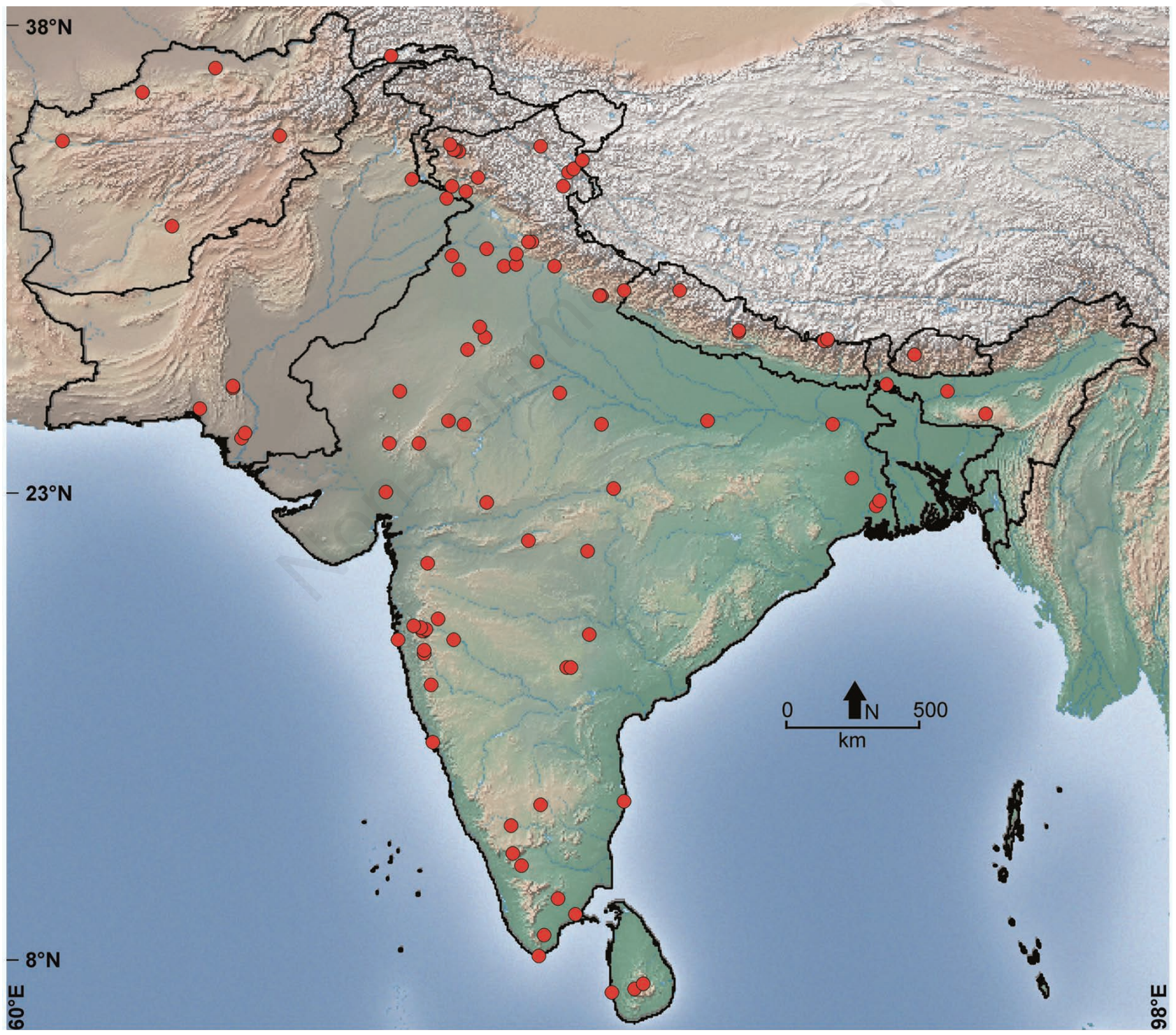

Fig. 1. Indian subcontinent considered for the study along with distribution of study sites (circles represent each locality). 
on Daphnia occurrence because a large number of Daphnia records from the sub-continent are dubious (Chatterjee et al., 2013). We only accepted records having at least some brief description of the animals with illustrations making possible a check of the identification of the cited species (for all records, see Supplementary Tab. 1). No reliable records of Daphnia could be obtained from Bangladesh and only a single report of $D$. tibetana was available from Bhutan (H. Dumont, pers. obs.).

Latitude and longitude data on each locality were obtained from Google Earth portal. A set of 19 bioclimatic variables and altitudes were extracted from the BIOCLIM dataset (http://www.worldclim.org; Hijmans et al., 2005) at ten-minute spatial resolution (for names see Tab. 1). Broad scale resolution was used as many of the localities given were quite nonspecific (Ex. Kolkata as a locality).

\section{Data analysis}

Environmental variables including latitude, longitude, altitude and the 19 bioclimatic variables were considered for statistical analysis. Univariate normality of each variable was checked using Shapiro-Wilk test. Since all variables proved to be non-normal, variables that were significantly different among Daphnia species were identified using non-parametric Kruskal-Wallis one-way analysis of variance. As multiple tests were performed, the family-wise error rate was corrected using Bonferroni correction.

Significant variables were then used in analyzing Daphnia distribution. The null hypothesis that the data is multivariate normal was checked using an omnibus test (Doornik and Hansen, 2008). Since the data was not multivariate normal, nonparametric multivariate analysis of variance (PERMANOVA) was used to find out whether given Daphnia species had significantly different requirements for environmental variables (Anderson, 2001). Relationship of Daphnia species distribution to the bio-climatic variables was investigated using canonical correspondence analysis (CCA). This analysis was performed using the statistically significant variables identified by a Kruskal Wallis test (Tab. 2) and the Daphnia occurrence data for all the 100 localities. The significance of the analysis was tested using Monte Carlo permutations $(\mathrm{n}=999)$. Statistical analysis was performed in PAST (Hammer et al., 2001).

\section{RESULTS}

Literature survey yielded a total of 134 records of Daphnia species from 100 different localities (Supplementary Tab. 2). The occurrence data were patchy in Northern and Central India, relatively well studied, while the Eastern, Northeastern region and North Western regions had a poorer coverage.

\section{Diversity and taxonomy}

Twelve species of Daphnia have been reported from the region (few comprising of presumable species groups) (Tab. 3), of which eight belong to the subgenus D. (Cten-

Tab. 1. Names of the BIOCLIM variables considered for the study.

\begin{tabular}{ll} 
BI0CLIM & \multicolumn{1}{c}{ Description } \\
\hline Bio1 & Annual mean temperature \\
\hline Bio2 & Mean diurnal range (mean of monthly) (max temp - min temp) \\
\hline Bio3 & Isothermality - (Bio2/Bio7) $(* 100)$ \\
\hline Bio4 & Temperature seasonality (standard deviation *100) \\
\hline Bio5 & Max temperature of warmest month \\
\hline Bio6 & Min temperature of coldest month \\
\hline Bio7 & Temperature annual range $($ Bio5-Bio6) \\
\hline Bio8 & Mean temperature of wettest quarter \\
\hline Bio9 & Mean temperature of driest quarter \\
\hline Bio10 & Mean temperature of warmest quarter \\
\hline Bio11 & Mean temperature of coldest quarter \\
\hline Bio12 & Annual precipitation \\
\hline Bio13 & Precipitation of wettest month \\
\hline Bio14 & Precipitation of driest month \\
\hline Bio15 & Precipitation seasonality (coefficient of variation) \\
\hline Bio16 & Precipitation of wettest quarter \\
\hline Bio17 & Precipitation of driest quarter \\
\hline Bio18 & Precipitation of warmest quarter \\
\hline Bio19 & Precipitation of coldest quarter \\
\hline
\end{tabular}

Tab. 2. Kruskal-Wallis one-way analysis of variance test for the environmental variables across different species. Underlined $\mathrm{P}$ values are significant after Bonferroni correction.

\begin{tabular}{|c|c|c|}
\hline Environmental variables & K & $\mathbf{P}$ \\
\hline Latitude & 57.6771 & $<0.0001$ \\
\hline Longitude & 18.0821 & 0.0797 \\
\hline Altitude & 44.8522 & $\leq 0.0001$ \\
\hline Biol & 50.1070 & $\leq 0.0001$ \\
\hline Bio2 & 26.4818 & 0.0055 \\
\hline Bio3 & 48.3185 & $\leq 0.0001$ \\
\hline Bio4 & 50.2673 & $<0.0001$ \\
\hline Bio5 & 45.4429 & $\leq 0.0001$ \\
\hline Bio6 & 62.5901 & $\leq 0.0001$ \\
\hline Bio7 & 37.2495 & $\underline{0.0001}$ \\
\hline Bio8 & 39.9302 & $\leq 0.0001$ \\
\hline Bio9 & 46.2505 & $<0.0001$ \\
\hline Bio10 & 45.3273 & $\leq 0.0001$ \\
\hline Bio11 & 63.4260 & $\leq 0.0001$ \\
\hline Bio12 & 25.4819 & 0.0077 \\
\hline Bio13 & 21.8519 & 0.0255 \\
\hline Bio14 & 13.7414 & 0.2476 \\
\hline Bio15 & 21.0657 & 0.0327 \\
\hline Bio16 & 22.0630 & 0.0239 \\
\hline Bio17 & 14.5532 & 0.2039 \\
\hline Bio18 & 13.0524 & 0.2899 \\
\hline Bio19 & 28.8192 & 0.0024 \\
\hline
\end{tabular}


odaphnia), and four to the subgenus Daphnia s.str. Among them, Daphnia $(C$.) lumholtzi and D. (C.) carinata s.l. are the most commonly reported species, while $D$. (D.) dentifera and $D$. (D.) obtusa s.l. have only two records each. Daphnia (D.) pulex was the most frequently reported Daphnia s.str. species followed by $D$. (D.) longispina. The highest number of species considering both sub-genera was observed at higher latitudes $\left(>25^{\circ} \mathrm{N}\right)(9$ species $)$ and at low and mid altitudes ( 8 species) and decreased at high altitudes (>5000 m asl) (5 species) (Fig. 2 b,d) and lowlands.

\section{Distribution patterns}

The widely distributed Daphnia species (both Daphnia and Ctenodaphnia) showed similar ranges of annual mean temperature and seasonality (Tab. 3; Supplementary Tab. 2). Daphnia (C.) carinata s.1. was seen in localities having a wide range of temperatures and high seasonality while $D$. (C.) cephalata s.l. and $D$. (C.) similis s.1. had much narrower ranges of seasonality. $D$. (C.) cephalata s.1. and D. (C.) similoides, restricted to south India (Fig. $3 \mathrm{~b}$ ), showed similar temperature seasonality ranges. Daphnia (D.) longispina s.l. was observed at a wider range of average annual temperatures. Ranges of annual mean temperature broadly corresponded with the latitudinal and altitudinal distribution pattern seen in both Daphnia s.str. and D. (Ctenodaphnia) (Tab. 3; Fig. 2 a,c).

The highest species number has therefore been reported from higher latitudes and mid altitudes (median value of altitude for the study area is $2500 \mathrm{~m}$ ) while the trans-Himalayas, the highest altitudinal and lowest temperature zones of the sub-continent seem to be the most impoverished zones, with only two species, i.e. D. (C.) $t i$ betana and $D$. (D.) dentifera (Fig. 2 a and b, respectively). It was demonstrated earlier that these taxa prefer high altitudes (Manca et al., 1994, 1998, 2006; Möst et al., 2013; Ma et al., 2015).
Based on temperature, latitudinal and altitudinal distribution patterns of Daphnia, three groups of species were observed:

a) Widely distributed taxa belonging to species complexes of both Daphnia and Ctenodaphnia subgenera, widely distributed in Eurasia (both in Palaearctic and Oriental zones): D. (D.) pulex s.1., D. (D.) longispina s.1., D. (C.) magna s.1., D. (C.) similis s.1., D. (C.) lumholtzi;

b) Elements restricted to the high altitudinal Himalayan region: D. (C.) fusca, D. (C.) tibetana and D. (D.) dentifera;

c) Species restricted to lower latitudes with truly tropical climate (only Ctenodaphnia): D. (C.) cephalata and $D$. (C.) similoides, as also reported by Benzie (2005).

\section{Environmental effects on distribution}

Latitude, altitude and almost all bioclimatic variables pertaining to temperature were significant in determining Daphnia species distribution while none of the precipitation variables were significant, an unexpected conclusion (Tab. 2). The null hypothesis that all Daphnia species and species groups had similar requirements of environmental variables was rejected as per PERMANOVA (permutations $=9999, \mathrm{~F}=8.423, \mathrm{P}<0.001)($ Supplementary Tab. 3).

The first two CCA axes explained $61.66 \%$ of variance (permutations $=9999$; trace $=1.775 ; \mathrm{P}<0.001$ ) (Fig. 4). Altitude correlated positively on the first axis $(\mathrm{r}=0.72)$ while almost all the temperature climatic variables correlated negatively with Mean Temperature of Warmest Quarter $(\mathrm{r}=-0.69)$ and Annual mean temp $(\mathrm{r}=-0.67)$ being the highest. Latitude $(\mathrm{r}=-0.58)$ was negatively correlated with the second axis while Isothermality $(\mathrm{r}=0.54)$ correlated positively with the second axis.

Distribution of all the species and possible species groups of the sub-genus Daphnia positively correlated with latitude, altitude and negatively correlated with tem-

Tab. 3. List of species reported from the Indian subcontinent along with ranges of annual mean temperatures of their respective localities. See literature sources in Supplementary Tab. 1.

\begin{tabular}{lc} 
Species & Annual mean Temperature range $\left({ }^{\circ} \mathrm{C}\right)$ \\
Daphnia (Ctenodaphnia) carinata King, $1853 \mathrm{s.1.}$ & -6.8 to 29.1 \\
\hline Daphnia (Ctenodaphnia) cephalata King, $1853 \mathrm{s.1}$ & 22.3 to 28.8 \\
\hline Daphnia (Ctenodaphnia) fusca Gurney, 1906 & -1.1 to 26.7 \\
Daphnia (Ctenodaphnia) lumholtzi Sars, 1885 & 15.3 to 27.3 \\
\hline Daphnia (Ctenodaphnia) magna Straus, 1820 & 11.7 to 28.6 \\
Daphnia (Ctenodaphnia) similis Claus, 1876 s.lat. & 24.1 to 25.8 \\
\hline Daphnia (Ctenodaphnia) similoides Hudec, 1991 & 15.8 to 27 \\
Daphnia (Ctenodaphnia) tibetana (Sars, 1903 ) & -3.8 to 8.7 \\
\hline Daphnia (Daphnia) dentifera Forbes, 1893 & -1.3 \\
Daphnia (Daphnia) longispina (O.F. Müller, 1776) s.l. & 4.9 to 28 \\
\hline Daphnia (Daphnia) obtusa Kurz, 1874 emend. Scourfield, 1942 s.l. & 13.7 and 15.2 \\
Daphnia (Daphnia) pulex Leydig, 1860 s. 1. & -3.8 to 26.7
\end{tabular}


perature variables. For the subgenus Ctenodaphnia, three groups, based on the groups mentioned earlier, could be singled out, with distribution determined by latitude and altitude. D. (C.) cephalata s.1. and D. (C.) similoides were observed in localities where the variations in the temperatures were less. Conversely, D. (C.) tibetana and $D$. (C.) fusca were observed in localities having lower mean temperatures and a higher annual temperature variation.
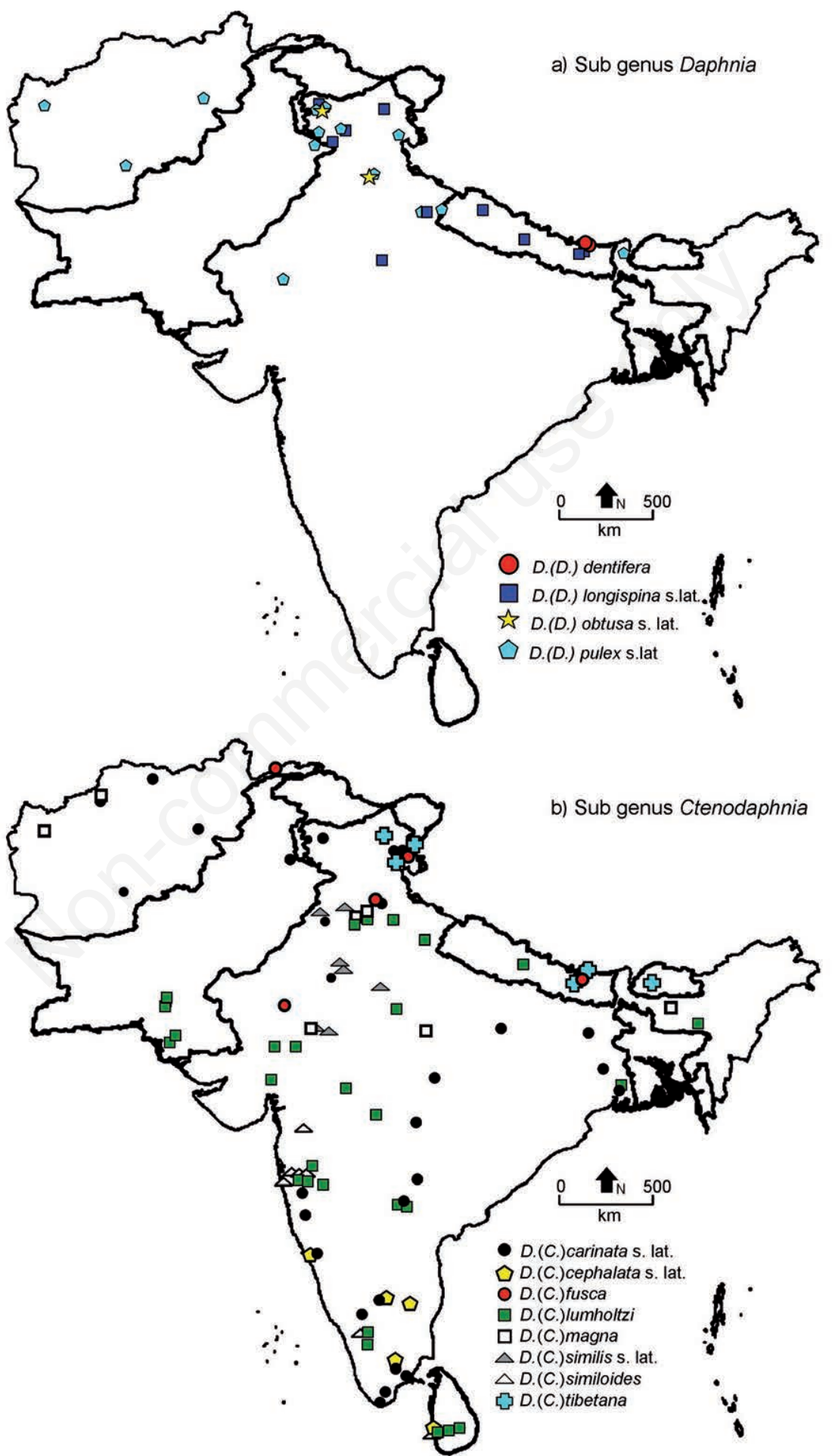

Fig. 2. Distribution of taxa from the a) subgenus Daphnia and b) subgenus Ctenodaphnia. 


\section{DISCUSSION}

\section{Confused taxonomy prevents final biogeographic conclusions}

With the old concept of 'cosmopolitanism' in zooplankton being replaced by 'continental endemism' or 're- gional endemism' (Gomez et al., 2000; Fontaneto, 2011; Marrone et al., 2013), biogeographical studies of the components of this community have become more relevant. Cladoceran investigations currently provide many good examples of non-cosmopolitanism in the water fleas (Frey, 1987; Xu et al., 2009). a)

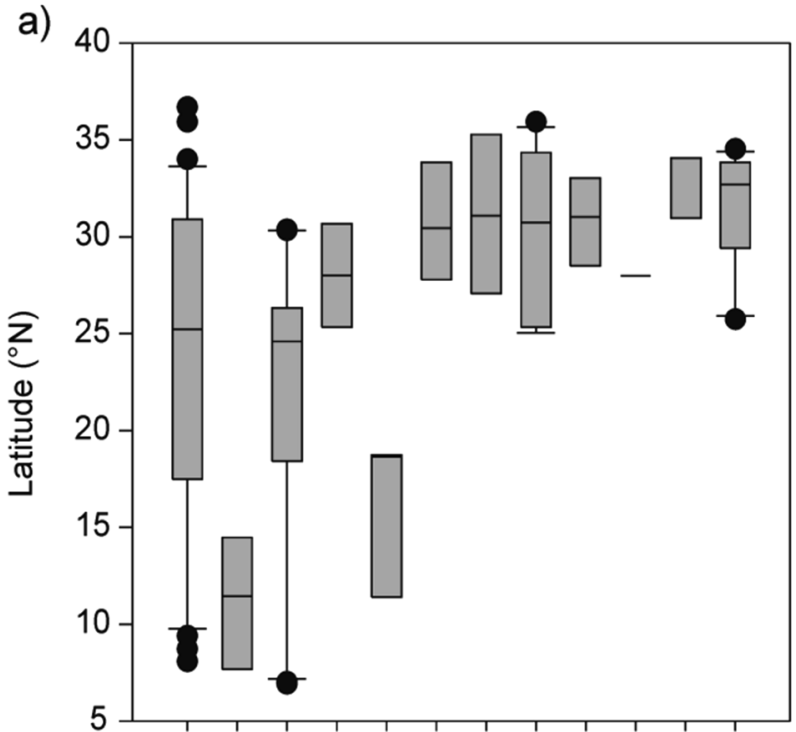

c)

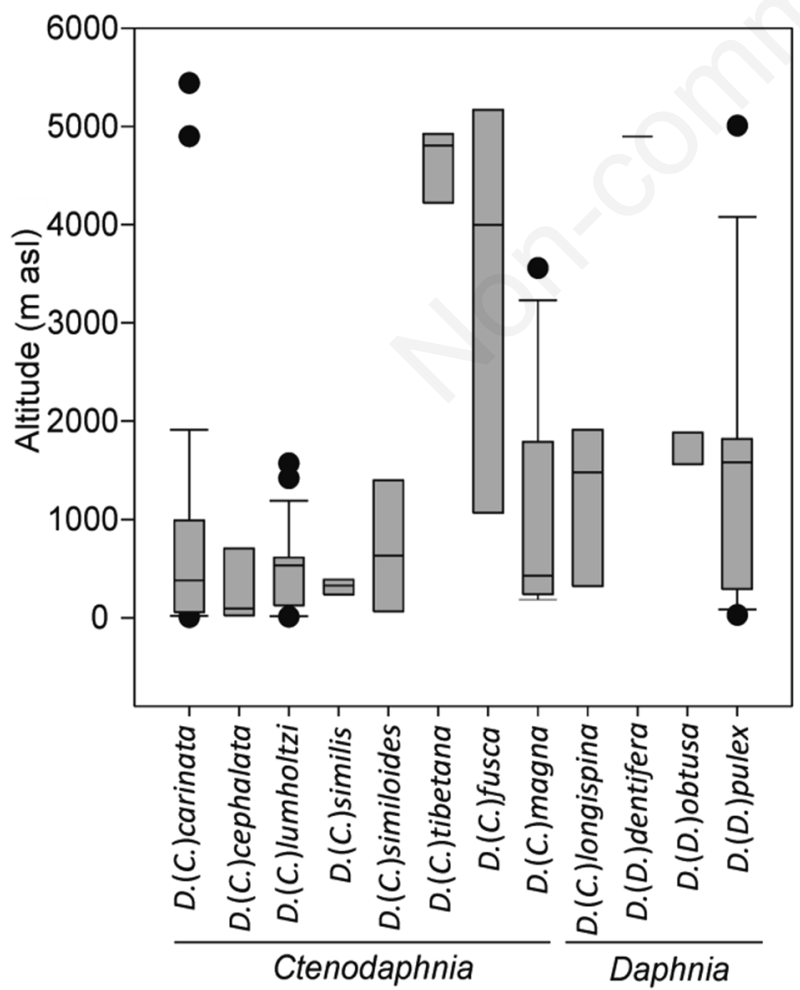

b)
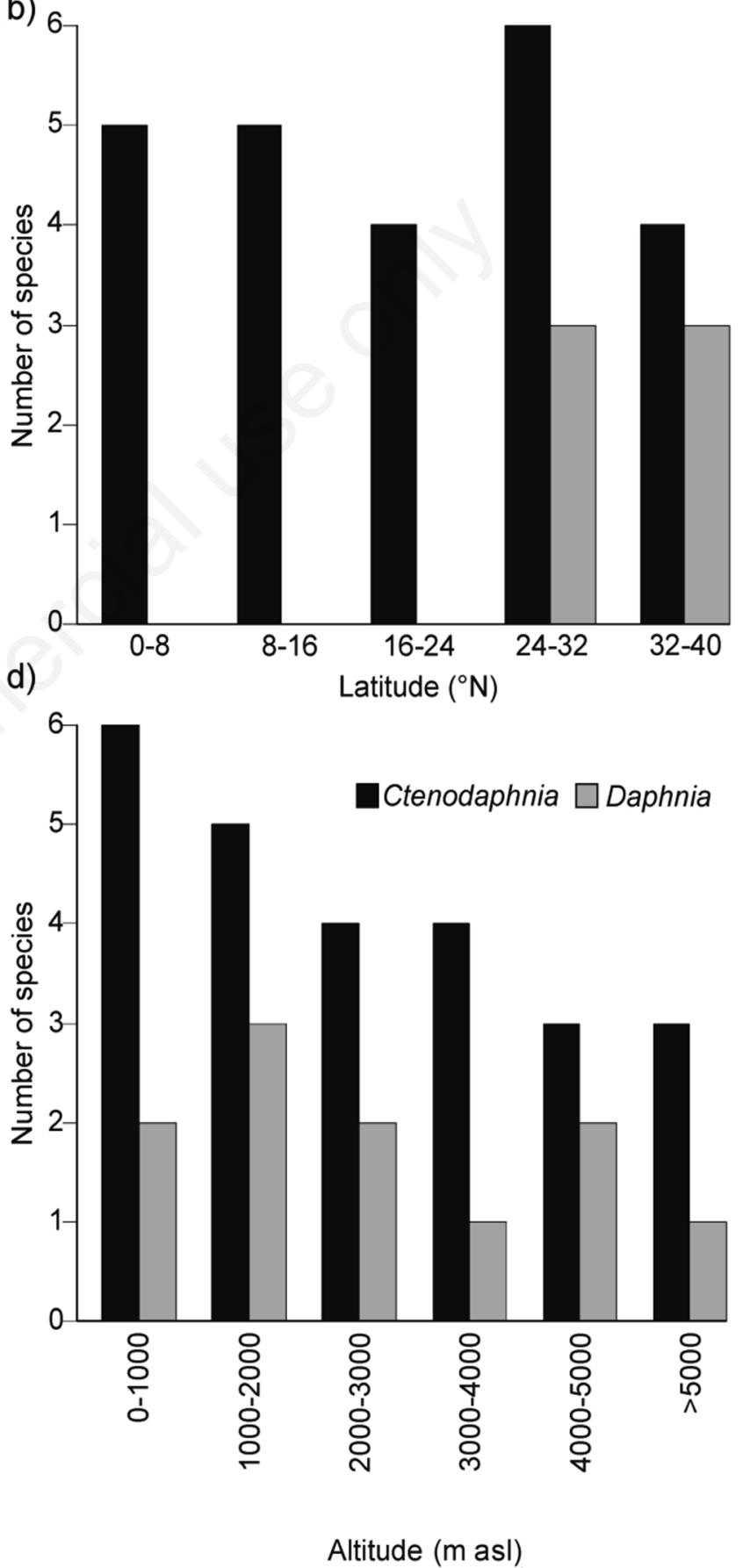

Fig. 3. a,c) Latitudinal and altitudinal ranges of all species. b,d) Total number of species of both sub genera observed across latitudinal and altitudinal classes. 
The Indian sub-continent hosts only about $3.5 \%$ of the known Daphnia species (Popova and Kotov, 2013) with only few known regional endemics like Daphnia $(C$.) fusca Gurney, 1906 and D. (C.) similoides Hudec, 1991. This situation is most likely an artifact due to: i) a large area of the sub-continent remaining unexplored (Fig. 1), ii) nomenclatural inconsistencies in using of names in different geographical regions (Benzie, 2005; Petrusek et al., 2008), namely a formal assignment of the Indian populations to European taxa without detailed morphological analysis (see Kotov and Taylor, 2010; Chatterjee et al., 2013; Kotov, 2015); and iii) lack of DNA sequence data, which are becoming essential to Daphnia taxonomy in the light of the existence of complexes of cryptic or pseudocryptic species (Kotov, 2015).

Incomplete taxonomic and faunistic data of the Cladocera has long held up its zoogeographical study (Frey, 1987; Dumont and Negrea, 2002). True cosmopolitans are rare (Dumont, 1994; Crease et al., 2012) while most species and phylogroups are limited in distribution (Havel and Shurin, 2004; Xu et al., 2009). Detailed morphological and molecular studies across various regions have started resolving ranges in a more fine-grained way (Adamowicz et al., 2009). Highly prevalent Daphnia groups like D. (C.) carinata s.1., D. (D.) longispina s.1. and $D$. (D.) pulex s.l. are now understood to be species complexes having regionally restricted elements in differ- ent regions of the planet (Hebert and Wilson, 1994; Taylor et al., 1996; Crease et al., 2012).

There are undoubtedly more cryptic lineages of Daphnia yet to be discovered in Africa and Asia (Adamowicz et al., 2009). A comparative analysis with other areas of the world at this stage can only be tentative. Based on the currently available data (i.e., Chatterjee et al., 2013), the Indian species richness is lower than that of China, where 20 species are reported to occur (Xiang et al., 2015) but it is higher than that of South-East Asia (3 species of Ctenodaphnia, Hudec, 1991; Korovchinsky, 2013). A thorough re-evaluation of the taxa listed above as 's.l.' could significantly increase the number of Indian species, though, 's.l.' taxa could themselves be also a subject of biogeographic studies (Fontaneto et al., 2011).

\section{Distribution of Daphnia}

Distribution of Daphnia species in the region corresponds to their known preferences in terms of latitude and altitude. Indeed, Daphnia (D.) longispina s.1., D. (D.) pulex s.l. and $D$. $(C$.) tibetana are restricted to northern regions while species like $D$. $(C$.) cephalata s.l. and $D$. (C.) similoides occur only at lower latitudes (Benzie, 2005) (Fig. 3 a,b). This implies particular environmental requirements of temperature and restriction to specific altitudes and latitudes altitude and latitude (Fig. 4; Supple-

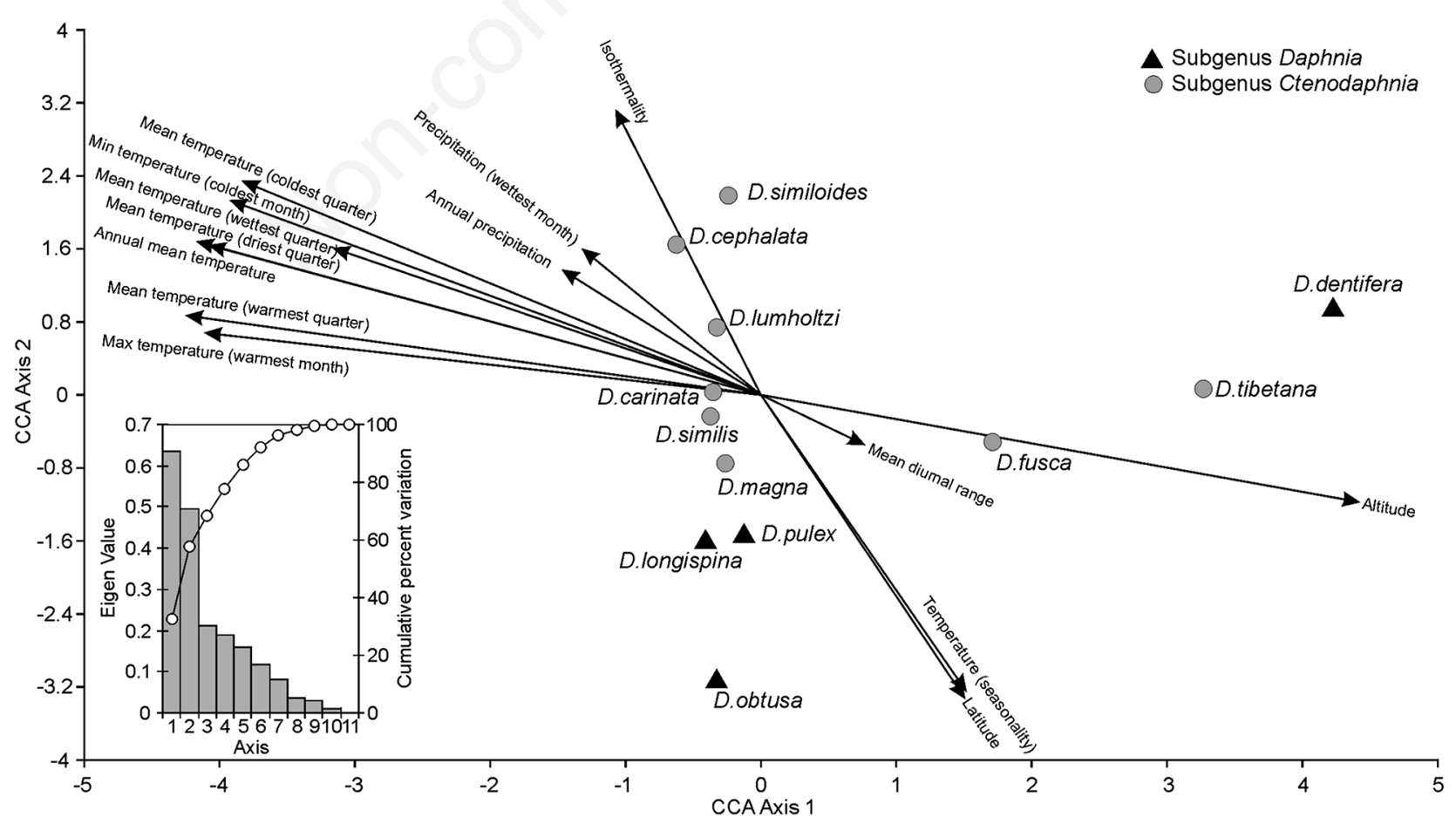

Fig. 4. Canonical correspondence analysis for Daphnia species and the environmental variables. Scree plot is provided in the inset. 
mentary Tab. 3). Contrastingly, widespread species like $D$. (C.) carinata s.l. and D. (C.) lumholtzi occurring in a wide range of altitude and latitude were shown to be tolerant to a wide range of environmental (temperature) necessities (Fig. 4), as evident from the CCA analysis. Latitude (along with temperature and altitude) clearly separated the Daphnia s.str. species from the D. (Ctenodaphnia) species, and the high altitudinal endemics from the widely distributed species complexes (Fig. 4). The species richness patterning in subgenus Daphnia s.str. observed in the study area further confirmed the bipolar distribution observed in these cladocerans (Dumont, 1980; Popova and Kotov, 2013). Increasing diversity toward the tropics is a pattern shared across a broad range of animal taxa (Hillebrand, 2004; Mittelbach et al., 2007) but there are numerous exceptions in insect groups like Ephemeroptera, Plecoptera and crustaceans like Anostraca (Boyero et al., 2011; Rogers, 2014). Observations by Fernando (1980) that all representatives of the subgenus Daphnia are restricted to $>24^{\circ} \mathrm{N}$ in the Indian subcontinent can be supplemented by the difference in average temperature between the optimum zones for survival of Daphnia $\left(25-50^{\circ} \mathrm{N}\right)$ and the true tropics (Korovchinsky, 2006) (for the study area, median annual temperature for $6-24^{\circ} \mathrm{N}$ zone $=25.3^{\circ} \mathrm{C}$ and for $25-37^{\circ} \mathrm{N}$ zone $=18.05^{\circ} \mathrm{C}$ ). Irrespective of this difference, widely distributed Daphnia and Ctenodaphnia show overlapping ranges in many temperature and BIOCLIM variables, perhaps explaining why many of the species do not show significantly different temperature requirements (Tab. 3; Supplementary Tab. 2). D. (C.) lumholtzi and D. (C.) carinata s.l. are restricted to regions that are permanently warm or have hot summer (Fryer, 1991) which was not seen to be the case (Tab. 3; Fig. 3 a,c). Mid altitudes $(1000-2000 \mathrm{~m}$ asl) harbored the maximum number of Daphnia species $(\mathrm{n}=9)$, while richness decreased with a further rise in altitude (Fig. 2d). The most common elevational pattern observed in species richness is a bell shaped distribution with highest numbers at the middle elevations (Lomolino, 2001). Very high altitudes (>3500 $\mathrm{m}$ asl) only sustained species like $D$. (D.) dentifera and $D$. (C.) tibetana (Fig. 3 a,b). Decline in productivity and resource diversity, unpredictable weather conditions and more UV radiation at high altitude are some of the possible reasons for lower species richness at high elevations (Cabrera et al., 1997; Dvorkin and Steinberger, 1999).

Various studies, however, provide evidence that mountainous regions in the lower latitudes harbor a number of endemic cladoceran taxa allied to more northern forms (Kotov et al., 2010) and that Daphnia species are often observed in the high altitudinal zones at lower latitudes of Africa and South America (Green, 1995; Kotov et al., 2010; Kotov and Taylor ,2010). Such 'Löffler Islands' ('high altitude regions containing cold water habi- tats with extra-tropical freshwater faunas' (sensu Van Damme and Eggermont, 2011) harboring endemic strains of Palaearctic Daphnia in Africa (Green, 1995; Van Damme and Eggermont, 2011) are not known at lower latitudes of the Indian sub-continent. Even widely distributed species complexes like $D$. (D.) pulex s.l., D. (D.) obtusa s.l. and $D$. (D.) longispina s.l. are not found commonly at higher altitudes regions of lower latitudes. This is an indication that other factors co-influence the distribution of planktonic Cladocera, and hence one should not be too rigid in interpretations of altitudinal distributions (Green, 1995).

\section{CONCLUSIONS}

We confirm the existence of three complexes of Daphnia in the Indian subcontinent: i) widely distributed species and species complexes; ii) high altitude endemics; and iii) low latitude D. (Ctenodaphnia) species. Only few species are found in tropical lowlands, with Daphnia s. str. completely absent. Also, we demonstrated that just temperature variation (as a result of altitudinal and latitudinal gradients) influenced Daphnia distribution, explaining some of the species groups observed.

\section{ACKNOWLEDGMENTS}

AAK was supported by Russian Government Program of Competitive Growth of Kazan Federal University. SP acknowledges Sanjay Molur, Wildlife Information Liaison Development society for their support.

\section{REFERENCES}

Adamowicz SJ, Petrusek A, Colbourne JK, Hebert PD, Witt JD, 2009. The scale of divergence: a phylogenetic appraisal of intercontinental allopatric speciation in a passively dispersed freshwater zooplankton genus. Mol. Phylogenet. Evol. 50: 423-436.

Anderson MJ, 2001. A new method for non-parametric multivariate analysis of variance. Austral. Ecol. 26:32-46.

Battish SK, 1983. Ecology and systematics of the Cladocera (Daphniidae: Branchiopoda) inhabiting Punjab, India. Res. Crust. 12:63-76.

Benzie JAH, 2005. The genus Daphnia (including Daphniopsis) (Anomopoda: Daphniidae), p. 1-383. In: H.J. Dumont (ed.) Guides to the identification of the microinvertebrates of the continental waters of the world. SPB Academic Publishing.

Boyero L, Pearson RG, Dudgeon D, Graça MAS, Gessner MO, Albariño RJ, Ferreira V, Yule CM, Boulton AJ, Arunachalam M, Callisto M, Chauvet E, Ramírez A, Chará J, Moretti MS, Gonçalves JF Jr, Helson JE, Chará-Serna AM, Encalada AC, Davies JN, Lamothe S, Cornejo A, Li AOY, Buria LM, Villanueva VD, Zúñiga MC, Pringle CM, 2011. Global distribution of a key trophic guild contrasts with common latitudinal diversity patterns. Ecology 92:1839-1848.

Briggs JC, 2003. The biogeographic and tectonic history of India. J. Biogeogr. 30:381-388. 
Cabrera S, López M, Tartarotti B, 1997. Phytoplankton and zooplankton response to ultraviolet radiation in a high-altitude Andean lake: short-versus long-term effects. J. Plankton Res. 19:1565-1582.

Chatterjee S, Scotese CR, 1999. The breakup of Gondwana and the evolution and biogeography of the Indian plate. Proc. Indian Natl. Sci. Acad. A 65:397-426.

Chatterjee T, Kotov AA, Van Damme K, Chandrasekhar SVA, Padhye S, 2013. An annotated checklist of the Cladocera (Crustacea: Branchiopoda) from India. Zootaxa 3667:1-89.

Crease TJ, Omilian AR, Costanzo KS, Taylor DJ, 2012. Transcontinental phylogeography of the Daphnia pulex species complex. PLoS One 7:1-11.

Doornik JA, Hansen H, 2008. An omnibus test for univariate and multivariate normality. Oxf Bull Econ Stat. 70:927-939.

Dumont HJ, 1980. Zooplankton and the science of biogeography: the example of Africa, p. 685-696. In W.C. Kerfoot (ed.), Evolution and ecology of zooplankton communities. University Press of New England.

Dumont HJ, 1994. On the diversity of the Cladocera in the tropics. Hydrobiologia 272:27-38.

Dumont HJ, Negrea SV, 2002. Introduction to the Class Branchiopoda, p. 1-398. In: H.J. Dumont (ed.), Guides to the identification of the micro invertebrates of the continental waters of the world. 19. Backhuys Publishers, Leiden.

Dvorkin AY, Steinberger EH, 1999. Modelling the altitude effect on solar UV radiation. Sol. Energy 65:181-187.

Fernando CH, 1980. The freshwater zooplankton of Sri-Lanka, with a discussion of tropical freshwater zooplankton composition. Int. Revue Ges. Hydrobiol. 65:85-125.

Fernando CH, Kanduru A, 1984. Some remarks on the latitudinal distribution of Cladocera on the Indian subcontinent. Hydrobiologia 113:69-76.

Fontaneto D, 2011. Biogeography of microscopic organisms. Is everything small everywhere? Systematics Association 79:1-365.

Frey DG, 1987. The taxonomy and biogeography of the Cladocera. Hydrobiologia. 145: 5-17.

Fryer G, 1991. Functional morphology and the adaptive radiation of the Daphniidae (Branchiopoda: Anomopoda). Philos. T. R. Soc. B 331:1-99.

Gomez A, Carvalho GR, Lunt DH, 2000. Phylogeography and regional endemism of a passively dispersing zooplankter: mitochondrial DNA variation in rotifer resting egg banks. P. Roy. Soc. Lond. B Bio. 267:2189-2197.

Gower DJ, Kupfer A, Oommen OV, Himstedt W, Nussbaum RA, Loader SP, Presswell B, Müller H, Krishna SB, Boistel R, Wilkinson M, 2002. A molecular phylogeny of ichthyophiid caecilians (Amphibia: Gymnophiona: Ichthyophiidae): out of India or out of South East Asia? Proc. R. Soc. Lond. B 269:1563-1569.

Green J, 1995. Altitudinal distribution of tropical planktonic Cladocera. Hydrobiologia 307:75-84.

Hammer Ø, Harper DAT, Ryan PD, 2001. PAST: Paleontological statistics software package for education and data analysis. Palaeontol. Elec. 4:1-9.

Havel JE, Shurin JB, 2004. Mechanisms, effects, and scales of dispersal in freshwater zooplankton. Limnol. Oceanogr. 49:1229-1238.

Hijmans R, Cameron SE, Parra JL, Jones PG, Jarvis A, 2005.
Very high resolution interpolated climate surfaces for global land areas. Int. J. Clim. 25:1965-1978.

Hillebrand H, 2004. On the generality of the latitudinal diversity gradient. Am. Nat. 163:192-211.

Hebert PDN, Wilson CC, 1994. Provincialism in plankton: endemism and allopatric speciation in Australian Daphnia. Evolution 48:1333-1349.

Hudec I, 1991. A comparison of populations from the Daphnia similis group (Cladocera: Daphniidae). Hydrobiologia 225:9-22.

Ishida S, Taylor DJ, 2007. Quaternary diversification in a sexual Holarctic zooplankter, Daphnia galeata. Mol. Ecol. 16: 569-582.

Karanth KP, 2003. Evolution of disjunct distributions among wet-zone species of the Indian subcontinent: Testing various hypotheses using a phylogenetic approach. Curr. Sci. 85:1276

Kerfoot WC, Lynch M, 1987. Branchiopod communities: association with planktivorous fish in space and time, p. 367378. In: W.C. Kerfoot and A. Sih (eds.), Predation: direct and indirect impacts on aquatic communities. Hanover University Press of New England.

Koehler F, Glaubrecht M, 2007. Out of Asia and into India: on the molecular phylogeny and biogeography of the endemic freshwater gastropod Paracrostoma Cossmann, 1900 (Caenogastropoda: Pachychilidae). Biol. J. Linn. Soc. 91:627- 651.

Korovchinsky NM, 2006. The Cladocera (Crustacea: Branchiopoda) as a relict group. Zool. J. Linn. Soc. 147:109-124.

Koro vchinsky NM, 2013. Cladocera (Crustacea: Branchiopoda) of South East Asia: history of exploration, taxon richness and notes on zoogeography. J. Limnol. 72(s2):e7.

Kotov AA, 2015. A critical review of the current taxonomy of the genus Daphnia OF Müller, 1785 (Anomopoda, Cladocera). Zootaxa 3911:184-200.

Kotov AA, Taylor DJ, 2010. A new African lineage of the Daphnia obtusa group (Cladocera: Daphniidae) disrupts continental vicariance patterns. J. Plankton. Res. 32:937-949.

Kotov AA, Taylor DJ, 2011. Mesozoic fossils (>145 Mya) suggest the antiquity of the subgenera of Daphnia and their coevolution with chaoborid predators. BMC Evol. Biol. 11:129.

Kotov AA, Sinev A, Berrios VL, 2010. The Cladocera (Crustacea: Branchiopoda) of six high altitude water bodies in the North Chilean Andes, with discussion of Andean endemism. Zootaxa 2430:1-66.

Kulkarni MR, Pai K, 2016. The freshwater diaptomid copepod fauna (Crustacea: Copepoda: Diaptomidae) of the Western Ghats of Maharashtra with notes on distribution, species richness and ecology. J.Limnol. 75:1269.

Lampert W, 2011. Daphnia: Development of a model organism in ecology and evolution. Excellence in Ecology. International Ecology Institute, Oldendorf/Luhe: $250 \mathrm{pp}$.

Lomolino M, 2001. Elevation gradients of species density: historical and prospective views. Global Ecol. Biogeogr. 10:3-13.

Ma X, Petrusek A, Wolinska J, Giessler S, Zhong Y, Yang Z, Hu W, Yin M, 2015. Diversity of the Daphnia longispina species complex in Chinese lakes: a DNA taxonomy approach. J. Plankton Res. 37:55-65.

Manca M, Cammarano P, Spagnuolo T, 1994. Notes on Cladocera and Copepoda from high altitude lakes in the Mount 
Everest Region (Nepal). Hydrobiologia 287:225-231.

Manca M, Ruggiu D, Panzani P, Asioli A, Mura G, Nocentini AM, 1998. Report on a collection of aquatic organisms from high mountain lakes in the Khumbu Valley (Nepalese Himalayas). Mem. Ist. Ital. Idrobiol. 57:77-98.

Manca M, Martin P, Carolina DP, Benzie JAH, 2006. Redescription of Daphnia (Ctenodaphnia) from lakes in the Khumbu Region, Nepalese Himalayas, with the erection of a new species, Daphnia himalaya, and a note on an intersex individual. J. Limnol. 65:132-140.

Mani MS, 1974. Ecology and biogeography in India. W. Junk Publ.: 647 pp.

Marrone F, Brutto SL, Hundsdoerfer AK, Arculeo M, 2013. Overlooked cryptic endemism in copepods: Systematics and natural history of the calanoid subgenus Occidodiaptomus Borutzky 1991 (Copepoda, Calanoida, Diaptomidae). Mol. Phylogenet. Evol. 66:190-202.

Mergeay J, Aguilera X, Declerck S, Petrusek A, Huyse T, De Meester L, 2008. The genetic legacy of polyploid Bolivian Daphnia: the tropical Andes as a source for the North and South American D. pulicaria complex. Mol. Ecol. 17:1789-1800.

Mittelbach GG, Schemske DW, Cornell HV, Allen AP, Brown JM, Bush MB, Harrison SP, Hurlbert AH, Knowlton N, Lessios HA, McCain CM, 2007. Evolution and the latitudinal diversity gradient: speciation, extinction and biogeography. Ecol. Let. 10: 315-331.

Möst M, Petrusek A, Sommaruga R, Juračka PJ, Slusarczyk M, Manca M, Spaak P, 2013. At the edge and on the top: molecular identification and ecology of Daphnia dentifera and D. longispina in high-altitude Asian lakes. Hydrobiologia 715: 51-62.

Petrusek A, Hobæk A, Nilssen JP, Skage M, Černý M, Brede N,
Schwenk K, 2008. A taxonomic reappraisal of the European Daphnia longispina complex (Crustacea, Cladocera, Anomopoda). Zool. Scr. 37:507-519.

Popova E, Kotov A, 2013. Latitudinal patterns in the diversity of two subgenera of the genus Daphnia OF Müller (Crustacea: Cladocera: Daphniidae). Zootaxa 3736:159-174.

Rogers DC, 2014. Anostracan (Crustacea: Branchiopoda) zoogeography I. North American bioregions. Zootaxa 3838: 251-275.

Taylor DJ, Hebert PDN, Colbourne JK, Kumar S, 1996. Phylogenetics and evolution of the Daphnia longispina group (Crustacea) based on 12S rDNA sequence and allozyme variation. Phylogenet. Evol. 5:495-510.

Van Damme K, Eggermont H, 2011.The Afromontane Cladocera (Crustacea: Branchiopoda) of the Rwenzori (Uganda-D. R. Congo): ecology, biogeography and taxonomy including the description of Alona sphagnophila $\mathrm{n}$. sp. Hydrobiologia 676:57-100.

Whatley R, Bajpai S, 2006. Extensive endemism among the Maastrichtian non-marine Ostracoda of India with implications for palaeobiogeography and "Out of India" dispersal. Rev. Esp. Micropaleontol. 38:229-244.

Xiang XF, Ji G, Chen S, Yu G, Xu L, Han B, Kotov AA, Dumont HJ, 2015. Annotated Checklist of Chinese Cladocera (Crustacea: Branchiopoda). Part I. Haplopoda, Ctenopoda, Onychopoda and Anomopoda (families Daphniidae, Moinidae, Bosminidae, Ilyocryptidae). Zootaxa 3904:1-27.

Xu S, Hebert PDN, Kotov AA, Cristescu ME, 2009. The noncosmopolitanism paradigm of freshwater zooplankton: insights from the global phylogeography of the predatory cladoceran Polyphemus pediculus (Crustacea, Onychopoda). Mol. Ecol. 18:5161-5179. 